\title{
UNMANNED AERIAL VEHICLE DERIVED 3D MODEL EVALUATION BASED ON ICESat-2 FOR ICE SURFACE MICRO-TOPOGRAPHY ANALYSIS IN EAST ANTARCTICA
}

\author{
Youquan $\mathrm{He}^{1,2}$, Gang Qiao ${ }^{1,2 *}$, Hongwei Li, Xiaohan Yuan, Yanjun Li \\ ${ }^{1}$ Center for Spatial Information Science and Sustainable Development, Tongji University, 1239 Siping Road, Shanghai, China - \\ (alenhe, qiaogang, LiHW, 1996yuanxiaohan)@tongji.edu.cn, yanjunli_1995@outlook.com \\ ${ }^{2}$ College of Surveying and Geo-Informatics, Tongji University, 1239 Siping Road, Shanghai, China
}

Commission TCIII, WG III/9

KEY WORDS: Modelling, Micro-topography, Unmanned Aerial Vehicle, SfM-MVS, ICESat-2, East Antarctica

\begin{abstract}
:
Modelling of ice sheet micro-topography based on Unmanned Aerial Vehicle (UAV) is meaningful for the understanding of interactions between local ice mass and climate. 3D reconstruction based on UAV has advantages that satellite remote sensing cannot replace. Here, the surface micro-topography measurement was performed during the China's 36th Antarctic expedition (CHINARE) in 2019-2020, using an UAV platform composed of a DJI Phantom 4 and a D-RTK GNSS mobile station around Zhongshan Station of China. Then, four partly overlapped models were obtained by the SfM-MVS technology. Affected by the complex environment factors, the performance of this technology sometimes is challenged over the marginal Antarctic Ice Sheet. Satellite altimetry is one of the most essential technologies for land ice surface elevation measurements, widely used in regional or global ice mass balance estimations. We use the land ice surface heights with high accuracy derived from the Ice, Cloud, and Land Elevation Satellite-2(ICESat2) to compare with the UAV-derived models. Combined with the high precision and space-time resolution of ICESat-2 satellite altimetry, the results of the model were evaluated under different terrain conditions. It has been certified that the derived models without extra GCPs were capable of detecting the surface micro-topographic features if considering the potential factors, which can be popularized and developed in polar research.
\end{abstract}

\section{INTRODUCTION}

Antarctica is one of the most sensitive and vulnerable regions in the global climate system. The Intergovernmental Panel on Climate Change (IPCC) in its sixth assessment cycle specially reported that the joint action of glacier and ice sheet is the main reason for the rapid global sea level rise (Oppenheimer et al., 2019). However, the interaction between climate and Antarctica ice sheet is not completely understood. Recently, more and more attention has been paid on the monitoring and analysis of the micro-topography evolution for ice sheets, which have important implications for polar research.

With the advance in accessibility of computer vision-based digital photogrammetry, UAV-based remote sensing has the potential to fill the gap between sparse and discontinuous field observations and continuous but coarse resolution space-borne remote sensing (Bhardwaj et al., 2016). As a new lightweight and available survey technology at very reasonable cost, UAV modelling is easy and quick to deploy and retrieve (Küng et al., 2011). The surface micro-topographic features of glaciers are more possibly reflected on high-solution orthophotos together with digital surface models (DSMs) derived from UAV, such as melt ponds, blue ice, crevasses and increased ice velocity (Qiao et al., 2020; Miles et al., 2018). Traditionally, using ground control points (GCPs) could ensure and improve the accuracy of UAV reconstruction during the geo-localization process. However, complex environment of polar region restricted the GCP measurement based on UAV in most cases, including the harsh weather, expensive logistics and the crevasse.
Without additional GCPs, the performance of this technology sometimes is challenged under a complex environment of the marginal Antarctic Ice Sheet. It is necessary to break through such limiting conditions with a more effective method. In this paper, based on the DJI real-time kinematic (D-RTK) Global Navigation Satellite System (GNSS) technology, we implemented the UAV-derived ice sheet micro-topography modelling without GCPs for polar research.

Satellite altimetry is one of the most essential technologies for land ice elevation measurements, widely used in regional or global ice mass balance estimations. It has incomparable advantages in depicting the dynamic changes of terrain in polar region. After ICESat mission, The Ice, Cloud, and Land Elevation Satellite-2 (ICESat-2) launched in 2018, utilizing the photon-counting lidar and ancillary systems (GPS and star cameras) for measuring the travel time from the Advanced Topographic Laser Altimetry System (ATLAS) to earth and back again and determine the photon's geolocation (Markus et al., 2017, Neumann et al., 2019). Laser pulses from ATLAS illuminate three left/right pairs of spots on the surface with a smaller footprint diameter size (ideally $\sim 17 \mathrm{~m}$ ). ICESat- 2 will provide scientists with height measurements that create a global portrait of Earth's 3rd dimension, gathering data that can precisely track changes of terrain. It has been proved to have a good performance in measuring the ice sheets elevation based on assessments of both its L3A Land Ice Height data (ATL06; Smith et al., 2019) data products. In support of ICESat-2, airborne lidar experiments were performed to validate the new satellite altimetry technology based on ground-based GPS survey and

\footnotetext{
* Corresponding author
} 
corner cube retro-reflector (CCR) technology (Brunt et al., 2017; Magruder and Brunt, 2018). before the launch, giving a surface elevation bias of less than $0.12 \mathrm{~m}$ and a precision of better than $0.09 \mathrm{~m}$ over the flat ice sheet interior (Brunt et al., 2017). After the launch, the results indicated an accuracy of $3 \mathrm{~cm}$ with a precision of $9 \mathrm{~cm}$ for ATL06 data (Release 001) using kinematic Global Navigation Satellite Systems (GNSS) technology in a 750 $\mathrm{km}$ ground-based traverse of the flat interior of the Antarctic ice sheet (Brunt et al., 2019). The Airborne Topographic Mapper (ATM) was used to assess the ATL06 data of ICESat-2 in Antarctica, over the marginal and interior Antarctic Ice Sheet during the overlapping mission time in November 2018, the ICESat-2 ice surface height was accurate to less than $0.14 \mathrm{~m}$ (Shen et al., 2020). Correspondingly, the team also used groundbased CCR arrays to validate ICESat-2 on-orbit performance along the $88 \mathrm{~S}$ traverse, determining its geolocation offset to be 2$5 \mathrm{~m}$ and an average beam diameter of $\sim 11 \mathrm{~m}$ (Magruder et al., 2020). Based on the general validation technologies above, ICESat-2 was believed to provide an available result that close to the ground truth dataset. We utilized the cooperative observation with laser altimetry satellite to achieve a comparison for the UAV derived $3 \mathrm{D}$ model. With that in mind, the vertical accuracy analysis has been performed using ICESat-2 land ice surface heights under various conditions. To explore the effect of the slope, distance to ground base station on the elevation difference compared with satellite altimetry data, the further analysis about these factors has been done. In this paper, we considered a series of UAV missions near Zhongshan station, and the result of UAV reconstruction has the potential to be applied for ice surface micro-topography detection if these effects could be concerned. This paper is as follows: Section 2 introduces the UAV platform, methods of image post-processing, study area and the comparison with ICESat-2; Section 3 shows the results of microtopography modelling and factors analysis; The conclusion and prospect are described in Section 4.

\section{METHOD AND STUDY AERA}

\subsection{UAV platform}

The DJI UAV technology was employed in this study. During the UAV survey, we use a mixed system including UAV, DJI Phantom 4 RTK (https://www.dji.com/phantom-4-rtk), and a DRTK GNSS mobile station (https://www.dji.com/cn/d-rtk2? site $=$ brandsite $\&$ from $=$ nav) for a UAV-derived model with high accuracy near Zhongshan station. DJI Phantom 4 RTK carried a 20-megapixel CMOS sensor for the capture of image data, and a DJI GS RTK app and Remote Controller with builtin screen were used to intelligently control UAV and clearly view. In some objective cases, it is difficult to build a ground control network to meet the requirements under the extreme climate conditions in Antarctica. This project uses GNSS RTK technology to obtain high-precision UAV photography position. Firstly, the base station is established, and the precise point positioning (PPP) technology is used to determine the position of the base station. Secondly, when the UAV flight is performed, the GNSS receiver and the base station carry out differential positioning. At the same time, the dual frequency receiver is used to eliminate the ionospheric delay. This method can obtain highprecision UAV photographing position without ground control points.

\subsection{SfM-MVS photogrammetry}

On the basis of ensuring enough side and course overlap of UAV images, the images obtained from the UAV surveys were postprocessed by the structure-from-motion multi-view stereo (SfM-
MVS) algorithm (Turner et al., 2014). Through feature matching, the homonymous features are extracted from multiple images, and the relative position of the camera is initially restored by beam adjustment. The nonlinear least square method is applied to optimize the camera position and pose and generate sparse point cloud. Finally, the dense point cloud is generated by multi view stereo algorithm, and the 3D modelling results are obtained. We applied the Pix4Dmapper software (version 4.5.6, https://support.pix4d.com/hc/en-us/categories/360001503192Pix4Dmapper) for this process without extra GCPs. The DSM and an orthophoto from each UAV survey were generated.

\subsection{Evaluation based on ICESat-2}

Considering the possible mobile station subsidence on ice surface and the long distance to the D-RTK GNSS mobile station in some UAV surveys, the absolute vertical position was found to have a nonlinear offset under the complex polar environment. In this paper, we used ICESat-2 ATL06 data in polar areas to conduct our evaluation research. ATL06 data were downloaded from the National Snow \& Ice Data Center (NSIDC) website (https://nsidc.org/data/ATL06/versions/3). ATL06 data is a Level-3A product containing time, latitude, longitude, and height above the World Geodetic System 1984 (WGS84) ellipsoid for each data point every $20 \mathrm{~m}$ (Smith et al., 2019), which provides estimates of the ice-sheet surface height, and related parameters to interpret and evaluate the quality of these height data. ATL06 heights represent the mean surface height along 40-m segments of ground track, 20-m apart, for each of ATLAS's six beams (ICESat-2 Technical Specs, 2020). Multiple geophysical corrections have been applied to its superior data products, including atmospheric effects, tides and solid earth deformations, to provide corrected heights. Two near-coincident ICESat-2 tracks passed through the area on the same day, and the ATL06 data were used to evaluate the UAV-derived 3D models. The raw ATL06 data points were checked by the quality parameter "atl06_quality_summary" and data points with potential problem were removed. The high-quality ATL06 elevation points would be treated as ground truth. For direct comparison with DSMs from section 2.2, the surface DSM-elevation values were extracted where every high-quality ATL06 data point locates. The mean difference between the ICESat- 2 elevation and the DSM elevation was calculated, which is assumed to be the surface elevation bias, and the standard deviation of the surface signal about the mean, which is assumed to be the 1-sigma surface measurement precision. According to these comparisons, further analysis would be done to verify the feasibility of this UAV technology and find out the potential impact factors.

\subsection{Study area}

The study area is located in the coastal Zhongshan Station, East Antarctica, near the China's base of departure along the exploration route on the Landsat- 8 images. The abundant microtopography of this area results a varied geography characteristic, with elevation values range from $30 \mathrm{~m}$ to $300 \mathrm{~m}$. Referring to the file of nominal mission orbits and beam locations download from ICEsat-2 website (https://icesat-2.gsfc.nasa.gov/science/specs) and the actual footprints from previous campaigns. During the 36th CHINARE in 2019-2020, four UAV survey missions in January 2020 were performed in coast of the ice sheet, East Antarctica, and two ICESat-2 tracks (one strong beam and one weak beam from track 0416) are shown (Figure 1). All missions were designed according to the coverage of ICESat-2 tracks for ice surface micro-topography research near the exploration route, and all surveys shared the same D-RTK GNSS mobile station with a flight height of $150 \mathrm{~m}$. The total length of ICESat-2 is up 
to $3,700 \mathrm{~m}$, containing the significant marginal characteristics. Details of the UAV surveys are listed (Table 1).

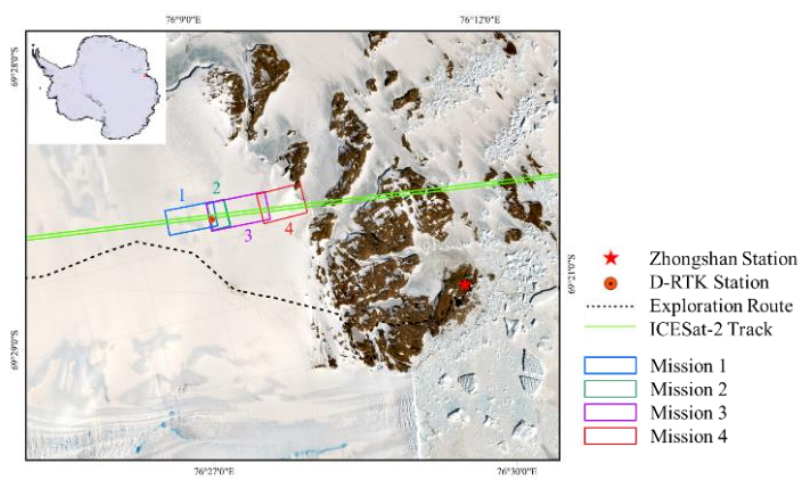

Figure 1. Location of the UAV surveyed areas on the background of Landsat- 8 images.

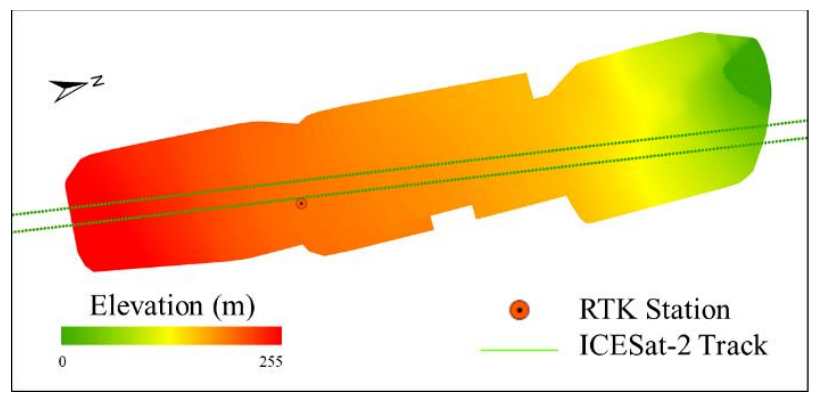

Figure 2. UAV Derived DSM

\begin{tabular}{ccccc}
\hline $\begin{array}{c}\text { Mission } \\
\text { ID }\end{array}$ & $\begin{array}{c}\text { Acquisition } \\
\text { date }\end{array}$ & $\begin{array}{c}\text { Area } \\
\left.\mathbf{( k m}^{2}\right)\end{array}$ & $\begin{array}{c}\text { Num of } \\
\text { images }\end{array}$ & $\begin{array}{c}\text { Flight } \\
\text { height } \\
(\mathbf{m})\end{array}$ \\
\hline 1 & $2020 / 01 / 22$ & 0.89 & 388 & 150 \\
2 & $2020 / 01 / 22$ & 0.36 & 114 & 150 \\
3 & $2020 / 01 / 22$ & 1.16 & 154 & 150 \\
4 & $2020 / 01 / 22$ & 0.93 & 283 & 150 \\
\hline
\end{tabular}

Table 1. Details of the UAV surveys.

\section{RESULTS}

\subsection{Micro-topography of marginal ice sheet}

The DSM and an orthophoto from each UAV survey were generated, and a total of $3.7 \mathrm{~km} \times 0.7 \mathrm{~km}$ area covering microtopography over a local marginal Antarctic Ice Sheet was built. High-resolution orthophoto and DSM generated from each UAV survey mission are displayed, including the high-resolution orthophoto (Figure 3) and the derived DSM (Figure 2). In the process of SfM-MVS, the initial image positions (green dots in Figure 4a) and camera attitude were reconstructed by beam adjustment. A gradual change was displayed in the direction from the inland to the marginal ice sheet from the terrain and its features.

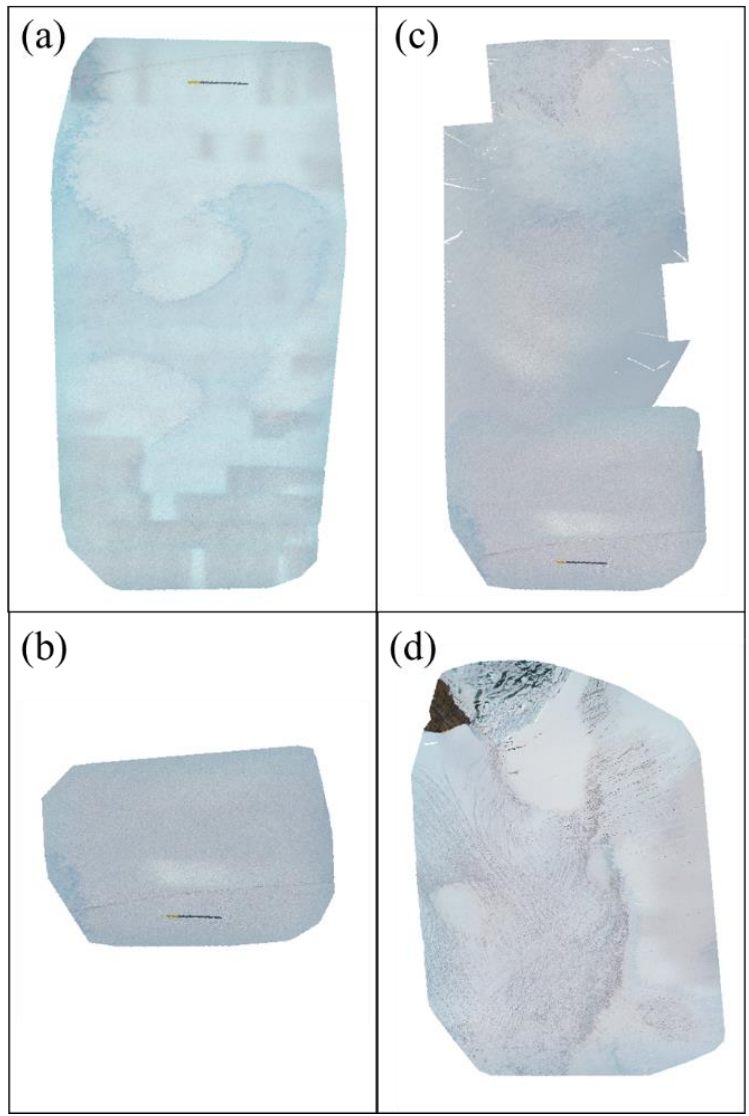

Figure 3. High-resolution orthophoto from mission 1 (a), mission 2 (b), mission 3 (c) and mission 4 (d).

The Antarctic ice sheet and glaciers keep moving, leading to significant changes in the micro-topography of the glacier surface, which may be slow or catastrophic. The UAV-derived models allow us to identify and extract the micro-topography features. Crevasses are important structural features that affect the stress condition and ice sheet stability of ice sheet. Moreover, their existence would be considered as a risk to human security, especially narrow crevasses that are hard to be detected by satellite images. UAV derived model not only provide clear imaging information but also 3D structures to measure the small and dangerous features (Figure 5d). In the inland area, the tiny characteristics (Figure 5c) resulting from wind and terrain reflect the local surface texture. In addition, it is more concrete and visible to describe the calving and retreat trend (Figure 5a and 5b) that often occurred in the region where meet the ocean through DSM product. Additionally, the plot of elevation profile (Figure 5e) identified that the UAV - derived DSMs were available to sense the potential depression of the ice surface and its change with such high resolution, providing more accurate depth and width estimates. 


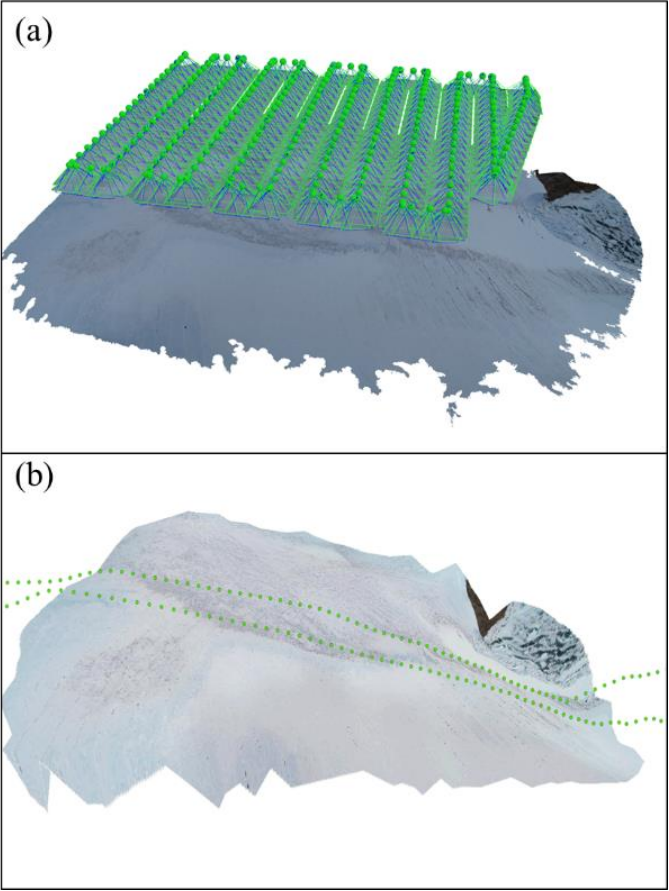

Figure 4. (a) The initial image position; (b) UAV-derived models and ICESat-2 tracks.

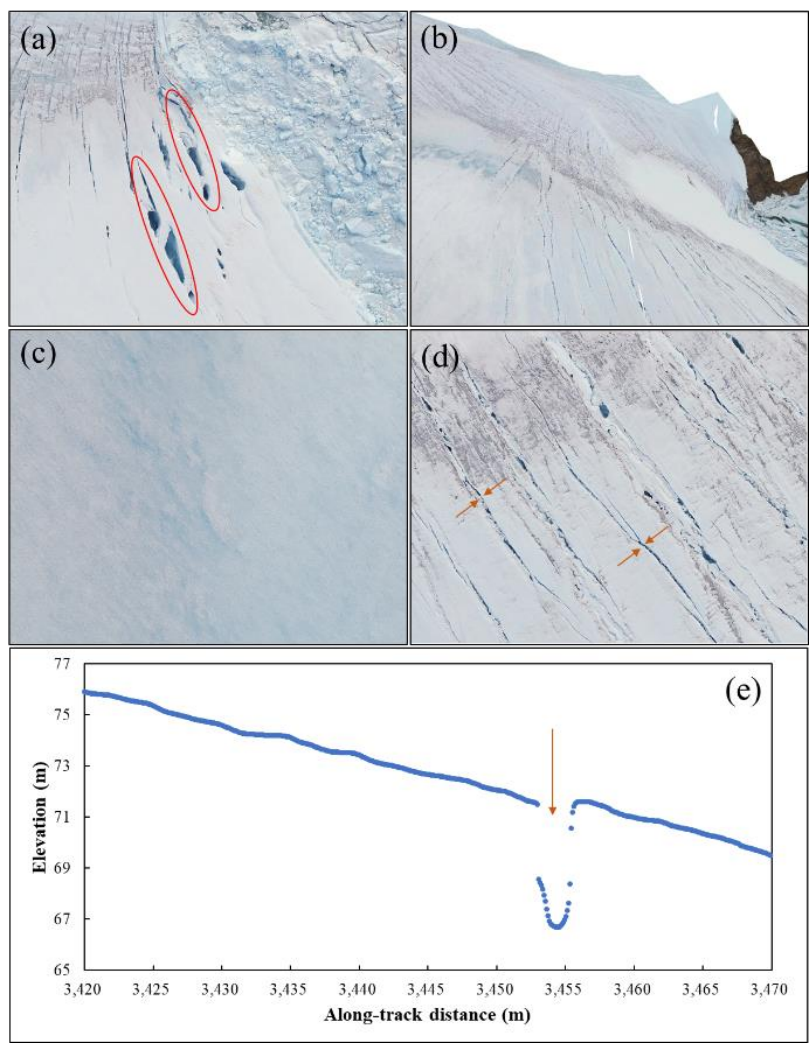

Figure 5. (a) (b) Calving and retreat trend at ice sheet front; (c) micro-topography of inland ice sheet; crevasses displayed on images (d) and DSMs (e).

\subsection{Evaluation}

Comparing with ICESat-2 in vertical direction, the bias and its standard deviation for each model are listed in Table 2, indicating a range of $0.24 \pm 0.05 \mathrm{~m} \sim 0.78 \pm 0.25 \mathrm{~m}$ for the ICESat- 2 strong beam, while the comparable result for weak beam, although there was a larger standard deviation of elevation difference. The data from strong beam may have more returned signal photons than weak beam, which lead a such difference. The elevation profile along the ICESat-2 track is shown in Figure 6. We zoomed several small segments from four UAV mission (1), (2), (3) and (4) in Figure 6), showing the difference between the two datasets. Considering the all surveys share the same station (red dot in Figure 1) and the nearly close time of flight, the impacts by the condition of itself can be ignored. With longer distance to D-RTK GNSS mobile station for each flight, the vertical offset of the UAV models without GCPs decreases significantly. Furthermore, the slope factor also should be concerned based on the analysis of Figure 4 and Table 2. Both mission 3 and mission 4 located in the region that far away from the mobile station. However, we found a quite remarkable bias difference (the value of mission 4 was twice as big as that of mission 3) but with an almost similar level of standard deviation value relative to the ICESat-2 elevation. From the point of view of elevation profile, the area of mission 4 is close to ocean and is with more complex steep terrain compared to the other. ATL06 data may be also affected by this factor, which can be ruled out according to the result of mission 1 with larger slope in inland region. the comparison results of four UAV surveys for ICESat-2 strong and weak beams and the relative average distance to the RTK station for each survey are displayed in Figure 7. The result indicated that there were no distinguishable differences between the strong beam and weak beam but superposition effect from distance to D-RTK GNSS mobile station appeared outstanding. In all, it indicated that the distance to D-RTK GNSS mobile station and terrain is the main error sources for UAV model reconstruction.

Strong beam

\begin{tabular}{|c|c|c|c|}
\hline Mission ID & Num of points & bias & $\begin{array}{l}\text { standard } \\
\text { deviation }\end{array}$ \\
\hline 1 & 70 & $+36.2 \mathrm{~cm}$ & $\pm 12.0 \mathrm{~cm}$ \\
\hline 2 & 27 & $+24.1 \mathrm{~cm}$ & $\pm 5.1 \mathrm{~cm}$ \\
\hline 3 & 85 & $+33.1 \mathrm{~cm}$ & $\pm 30.5 \mathrm{~cm}$ \\
\hline 4 & 63 & $+78.0 \mathrm{~cm}$ & $\pm 25.0 \mathrm{~cm}$ \\
\hline \multicolumn{4}{|c|}{ Weak beam } \\
\hline Mission ID & Num of points & bias & $\begin{array}{l}\text { standard } \\
\text { deviation }\end{array}$ \\
\hline 1 & 68 & $+26.4 \mathrm{~cm}$ & $\pm 18.4 \mathrm{~cm}$ \\
\hline 2 & 26 & $+17.1 \mathrm{~cm}$ & $\pm 18.8 \mathrm{~cm}$ \\
\hline 3 & 82 & $+30.3 \mathrm{~cm}$ & $\pm 38.7 \mathrm{~cm}$ \\
\hline 4 & 56 & $+75.0 \mathrm{~cm}$ & $\pm 23.1 \mathrm{~cm}$ \\
\hline
\end{tabular}

Table 2. The bias and its standard deviation for each model comparing with the ICESat-2 track. 


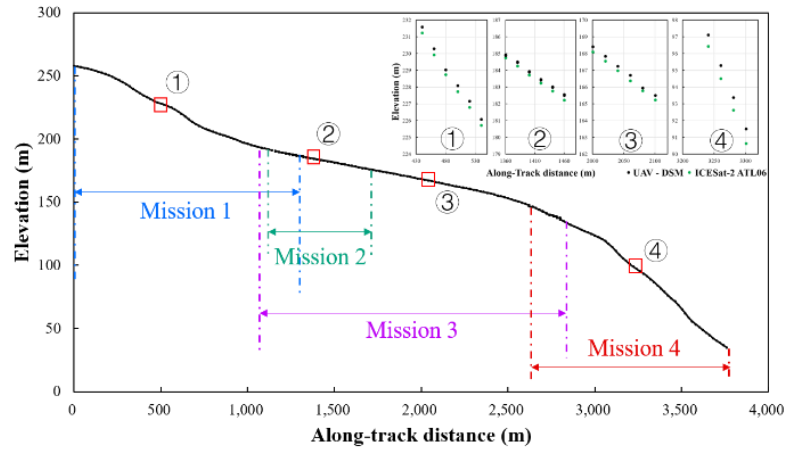

Figure 6. Elevation profile in study area along ICESat-2 track and the variable vertical offsets between DSM and ICESat-2.

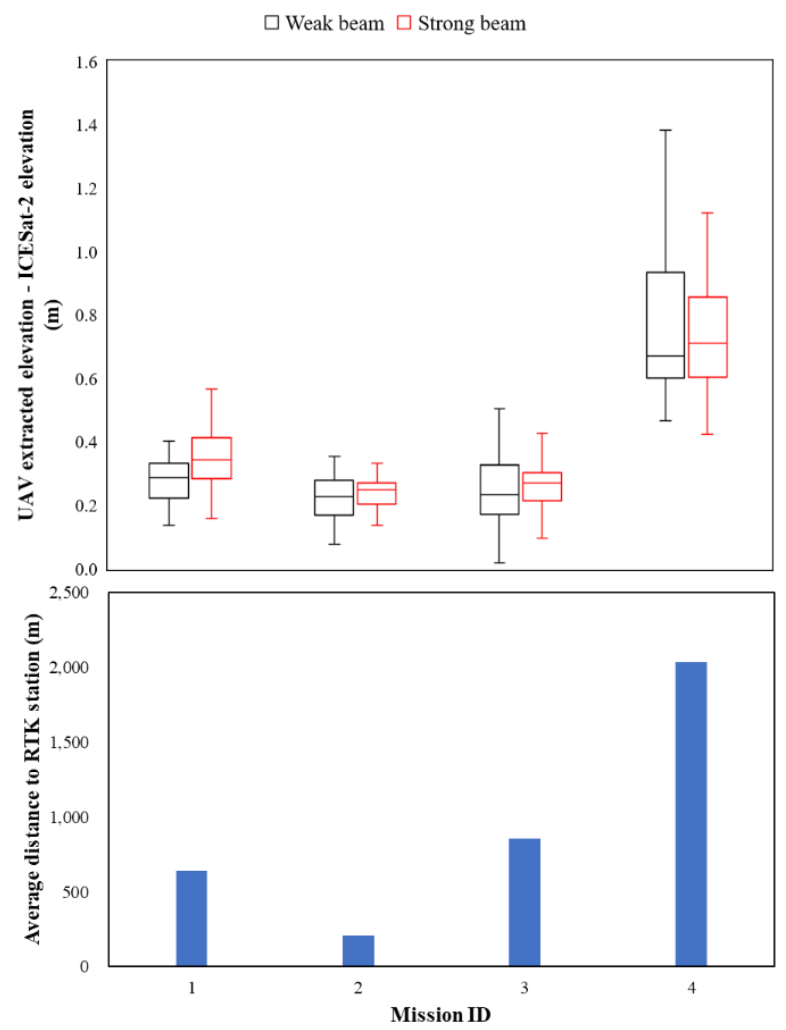

Figure 7. Boxplots of the UAV extracted elevation minus the ICESat-2 ATL06 elevation and corresponding average distance to RTK station for each survey. Outliers are not show in the boxplots.

\section{CONCLUSIONS}

In this paper, we utilized DJI UAV technology to implement the UAV survey without extra GCPs during the 36th CHINARE in East Antarctica. These results proved that it was feasible to implement aerial photogrammetry utilizing the UAV photography positioning technique without GCPs. The generation and evaluation of UAV 3D model for surface microtopography (such as calving and crevasses) study was conducted. Different from satellite remote sensing, the detection resolution and efficiency can be improved by 3D reconstruction based on UAV, especially among key areas. The ICESat- 2 elevation points give a chance to check the accuracy of $3 \mathrm{D}$ models relatively, providing the improvement strategy for this applicable observation technique in polar regions. We concluded that the vertical accuracy of the UAV models without GCPs decreases significantly with the distance to D-RTK GNSS mobile station, especially with great gradient variation. These factors shall be concerned in future applications. Overall, the DJI UAV technology can achieve an acceptable result without ground measurement support in some polar extreme scenarios. In the later research, the other near-coincident observations could be considered as virtual GCPs to improve the shortcomings above by selecting suitable mathematical correction models, expanding the UAV application in polar region.

\section{ACKNOWLEDGEMENTS}

This research was supported by the National Key Research \& Development Program of China (No. 2017YFA0603102 and 2017YFB0503502), the National Science Foundation of China (41771471, 41941006, and 42011530088).

\section{REFERENCES}

Bhardwaj, A., Sam, L., Akanksha, Martín-Torres, F. J., and Kumar, R., 2016. UAVs as remote sensing platform in glaciology: Present applications and future prospects. Remote Sensing of Environment, 175, 196-204.

Brunt, K. M., Hawley, R. L., Lutz, E. R., Studinger, M., Sonntag, J. G., Hofton, M. A., Andrews, L. C., and Neumann, T. A., 2017. Assessment of NASA airborne laser altimetry data using groundbased GPS data near Summit Station, Greenland, The Cryosphere, 11(2), 681-692.

Brunt, K. M., Neumann, T. A., and Smith, B. E., 2019. Assessment of ICESat-2 ice sheet surface heights, based on comparisons over the interior of the Antarctic ice sheet. Geophys. Res. Lett., 46(22), 13072-13078.

ICESat-2 Technical Specs: https://icesat2.gsfc.nasa.gov/science/specs, last access: 27 September 2020.

Küng, O., Strecha, C., Beyeler, A., Zufferey, J. C., Floreano, D., Fua, P., and Gervaix, F., 2011. The accuracy of automatic photogrammetric techniques on ultra-light UAV imagery (No. CONF).

Magruder L. A., and Brunt K. M., 2018. Performance analysis of airborne photon-counting lidar data in preparation for the ICESat-2 mission. IEEE T. Geosci. Remote, 56(5), 2911-2918.

Magruder, L. A., Brunt, K. M., and Alonzo, M., 2020. Early ICESat-2 on-orbit geolocation validation using ground-based corner cube retro-reflectors, Remote Sensing, 12(21), 3653.

Markus, T., Neumann, T., Martino, A., Abdalati, W., Brunt, K., Csatho, B., Farrell, S., Fricker, H., Gardner, A., Harding, D., Jasinski, M., Kwok, R., Magruder, L., Lubin, D., Luthcke, S., Morison, J., Nelson, R., Neuenschwander, A., Palm, S., Popescu, S., Shum, B. E., Schutz, R., Smith, B., Yang, Y., and Zwally, J., 2017. The Ice, Cloud, and Land Elevation Satellite-2 (ICESat-2): Science requirements, concept, and implementation, Remote Sensing of Environment, 190, 260-273.

Miles, B. W. J., Stokes, C. R., and Jamieson, S. S. R., 2018. Velocity increases at cook glacier, east antarctica, linked to ice shelf loss and a subglacial flood event. The Cryosphere, 12(10), $3123-3136$ 
Neumann, T. A., Martino, A. J., Markus, T., Bae, S., Bock, M. R., Brenner, A. C., Brunt, K. M., Cavanaugh, J., Fernandes, S. T., Hancock, D. W., Harbeck, K., Lee, J., Kurtz, N. T., Luers, P. J., Luthcke, S. B., Magruder, L., Pennington, T. A., RamosIzquierdo, L., Rebold, T., Skoog, J., and Thomas, T. C., 2019. The Ice, Cloud, and Land Elevation Satellite-2 Mission: A global geolocated photon product derived from the Advanced Topographic Laser Altimeter System, Remote Sensing of Environment, 233, 111325.

Oppenheimer, M., B.C. Glavovic, J. Hinkel, R. van de Wal, A.K. Magnan, A. Abd-Elgawad, R. Cai, M. CifuentesJara, R.M. De Conto, T. Ghosh, J. Hay, F. Isla, B. Marzeion, B. Meyssignac, and Z. Sebesvari, 2019. Sea Level Rise and Implications for Low-Lying Islands, Coasts and Communities. In: IPCC Special Report on the Ocean and Cryosphere in a Changing Climate.

Qiao, G., Li, Y., Guo, S., Ye, W., 2020. Evolving instability of the scar inlet ice shelf based on sequential landsat images spanning 2005-2018. Remote Sensing, 12(1), 36(2020).

Shen, X., Ke, C. Q., Yu, X., Cai, Y., and Fan, Y., 2021. Evaluation of Ice, Cloud, And Land Elevation Satellite-2 (ICESat-2) land ice surface heights using Airborne Topographic Mapper (ATM) data in Antarctica. International Journal of Remote Sensing, 42(7), 2556-2573.

Smith, B., Fricker, H. A., Holschuh, N., Gardner, A. S., Adusumilli, S., Brunt, K. M., Csatho, B., Huth, A., Neumann, T., Nilsson, J., and Siegfried, M. R., 2019. Land ice height-retrieval algorithms for NASA's ICESat-2 photon-counting laser altimeter. Remote Sensing of Environment, 233, 111352.

Turner, D., Lucieer, A., and Wallace, L., 2014. Direct georeferencing of ultrahigh-resolution UAV imagery. IEEE T. Geosci. Remote, 52(5), 2738-2745. 